\title{
Coffmania, a new tanypod genus from the Darjeeling - Sikkim Himalayas, India (Diptera : Chironomidae)
}

\author{
N. Hazra ${ }^{1}$ \\ P. K. Chaudhuri ${ }^{1}$
}

Keywords : Diptera, Chironomidae, Coffmania, new genus, new species, rheobiontic, embenthic.

A new genus, Coffmania in the tribe Pentaneurini of the subfamily Tanypodinae with two new species from Darjeeling-Sikkim Himalayas in India is described and illustrated with male and female imagines, pupa and larva. Systematics of the genus and ecology of the species have also been discussed.

Coffmania, un nouveau genre de Tanypodinae (Diptera : Chironomidae) du Darjeeling-Sikkim (Himalaya, Inde)

Mots clés : Diptera, Chironomidae, Coffmania, nouveau genre, nouvelle espèce, rhéobionte, endobenthique.

Les imagos $\sigma^{\circ}$, les nymphes de deux espèces nouvelles de la région himalayenne, appartenant à un nouveau genre de Tanypodinae Coffmania de la tribu des Pentaneurini, sont décrits ainsi que l'imago $\$$ et la larve de l'espèce type C. animispina n. sp. La position systématique du genre et l'écologie des espèces sont aussi discutées.

\section{Introduction}

The chironomids, especially the Tanypodinae, of the Indian subregion are less well investigated in comparison to other zoogeographical regions. The finding of new taxon is therefore expected. During our survey of chironomid midges in the Darjeeling-Sikkim Himalayas, a few larvae were collected from the algal mass and also from the sediment of the springs of several places. On rearing, the adults alongwith the immatures appear as new species under a new genus in the tribe Pentaneurini. The male imagines are separable from other tanypods by the broad, setose, ovoid or triangular median volsella with or without lateral lobe; curved and uniformly tapered gonostylus; $\mathrm{C}$ slightly produced and ending proximal to $\mathbf{M}_{1+2}$; scutal tubercle well developed; AR 1.1-1.4 ; narrowest point of the ventral border of the dorsomedial eye extension concave ha-

1. Department of Zoology, University of Burdwan, Burdwan, 713 104, India. ving 3-4 ommatidia. The pupa is recognizable by apically bifurcate, upwardly directed horn sac and more or less circular or oval large plastron plate; corona; thoracic comb; scar on tergite I; dense shagreen mostly simple and posteromedially simple, bifid, multibranched spinules; 4 and 5 LS setae on segments VII and VIII respectively; moderately or strongly hooked anal lobe. The larval characteristics include cephalic index 0.64-0.70; AR 3.4-3.9, blade shorter than flagellum; apical half of mandible strongly narrowed and curved, basal tooth very short, no accessory tooth; length of segments of b-seta 3, 6 and 3; row of teeth of ligula concave, inner tooth distinctly outcurved; paraligula about 0.43 length of ligula; pseudoradula consisting of 7-8 parallel rows forming a band, weakly narrowed apically; subbasal seta of posterior parapod simple and 2 strong supraanal setae.

\section{Material and methods}

The larvae were collected from the algal masses and bottom sediments of the springs in the outskirts of Gangtok, Jorethang (Sikkim), Mirik (West Bengal) and were subjected to rearing in the laboratory. The 
imagines and the immatures are processed and mounted on microslides following the methods by Das Gupta \& Wirth (1968). The general morphological terminology follows Sæther (1980). The measurements of different parts of immatures and adults are taken with the help of microscope and micrometer and are expressed in micrometer $(\mu \mathrm{m})$. Howèver, total length of pupae and larvae, and total length and wing of adults are expressed in millimeter (mm). The measurements are given as ranges followed by «n» ensuring the number of specimens observed.

Types are at the Entomological collections of the University of Burdwan and will be deposited in National Zoological Collections (NZC) Calcutta, in British Natural History Museum (BMNH) London and in U.S. National Museum (USNM) Washington D. C., in due course.

\section{Coffmania gen. $\mathbf{n}$.}

Type species. Coffmania animispina sp. n. by present designation.

Etymology. The genus is named in honour of Pr. W. P. Coffman of Pittsburgh University in recognition of his valuable contributions to the study of Chironomidae.

\subsection{Diagnosis}

\section{- Male imago}

Small species; wing length 1.5-1.8.

Head. Eye with dorsomedial extension with 3-4 ommatidia at minimum width, ventral border of the eye extension especially at the narrowest point distinctly concave. Antenna. AR 1.1-1.4; pedicel yellow, terminal flagellomere not offset basally $3.2-4.5 \mathrm{x}$ as long as broad and tapering in the distal $1 / 3$. Head yellowish in colour. IV, OV and Po uniserial.

Thorax. Antepronotum well developed, lobes separated above with 5-6 lateral antepronotals; acrostichals biserial between the vittae, diverging in front of the scutal tubercle and ending in the prescutellar field, dorsocentrals irregularly biserial anteriorly, uniserial posteriorly, prealars numerous, mostly robust; scutal tubercle very distinct.

Wing. Membrane with setae with or without faint band; brachiolum with 2 setae; $C$ slightly produced beyond $R_{4+5}$, ending well before $M_{1+2}, R_{2+3}$ distinct, $\mathrm{FCu}$ before $\mathrm{MCu}$; anal lobe weakly developed.

Legs. Pale yellow in colour; tibial spurs elongate with main tooth 0.5-0.65 spur length and 5-8 lateral teeth; tibial comb of 5-7 setae present on hind leg; $\mathrm{Ta}_{3}$ on mid leg with or without tarsal brush; claws slender, distally pointed; pulvilli absent.

Abdomen. Yellow to light brown; posterior border of tergite IX concave, transverse row of setae present or absent.

Hypopygium. Anal point broad and conical; gonocoxite robust more or less cylindrical, 1.4-1.5 $\mathrm{x}$ as long as broad, inner border straight, outer border convex, slightly tapered distally, dorsomedian surface with 15-18 large, erect apical setae; median volsella broad, setose, ovoid or triangular in shape with or without finger-like lateral.lobe; gonostylus long, slender, curved with swollen base bearing large megaseta; phallapodeme distinct, simple, sternapodeme pointed anteriorly.

\section{- Female imago}

Similar to male except for following differences : AR 0.22-0.26; antenna 12 segmented. $\mathrm{LR}_{1}$ 0.81-0.87, $\mathrm{LR}_{2}$ 0.60-0.66 and $\mathrm{LR}_{3}$ 0.73-0.74. Genitalia with well developed gonocoxite VIII bearing few strong setae; segment X normal; gonapophysis VIII with large ventrolateral lobe; apodeme lobe with curved and distinct apodeme; cercus small; seminal capsule round with well developed sclerotized neck; notum long with strongly diverged rami.

\section{- Pupa}

Small to medium sized pupae, up to 4.70 long. Exuviae pale brown.

Cephalothorax. Thoracic horn flattish, swollen apically and 1.55-2.1 x as long as broad, external membrane spinose, horn sac tubular, apically bifurcated overlapping to the plastron plate, plastron plate oval or circular in shape, corona present, occupying $0.40-0.70$ horn length; thoracic comb present but weak; small basal lobe present. Thoracic membrane spinose. Scutal tubercle and postnotal tubercle absent. Thoracic setae $\mathrm{Dc}_{1}, \mathrm{Dc}_{2}$, and Sa simple, distally pointed.

Abdomen. Scar on tergite I elongated, lightly pigmented. Tergites and sternites with a dense covering of simple, bifid and multibranched shagreen spinules. Apophyses present. D and V setae filamentous, terminally round, $L$ seta filamentous on segment $I$ and simple on segments II-VI, longer than D seta. LS setae always present on segments VII-VIII. Anal lobe 2.18-2.30 $\mathrm{x}$ as long as broad, dorsal surface with simple spinules, inner border slightly convex with or without spinules and outer border concave distally with fine spinules, apex of anal lobe hooked; anal macrosetae without adhesive sheaths; male genital sac reaching $0.65-0.71$ of anal lobe length. 


\section{- Larva}

Medium sized larvae, up to 6 long. Head capsule elongate brown in colour, posterior margin blackish brown, head capsule longish-oval, cephalic index 0.64-0.70.

Antenna. AR 3.45-3.87; antenna almost $1 / 2$ as long as head, 2.25-2.40 $\mathrm{x}$ as long as mandible; basal segment about $10 \mathrm{x}$ as long as basal width, with ring organ at the base of apical 1/3, segment II about 8.5-9.5 $\mathrm{x}$ as long as wide, apical segment $3 / 4$ as long as segment III; style clubbed apically, reaching to about middle of last segment; blade somewhat shorter than fllagellum, blade about $4.5 \mathrm{x}$ as long as height of basal ring, basal ring $2 \mathrm{x}$ as high as wide, accessory blade shorter than blade.

Mandible. Apical $1 / 2$ of mandible strongly narrowed and curved, $2 \mathrm{x}$ as long as basal width, basal half $1 / 2$ strongly broadened, apical tooth $2.50 \mathrm{x}$ as long as basal width, about 1/4 length of mandible, distal $1 / 2$ blackish brown; basal tooth insignificant, seta subdentalis arising from dorsal side; accessory tooth not visible, ventrolateral setae adjacent to the outer margin of basal 1/2 of mandible, sensillum minusculum situated proximal to seta III, ventrolateral seta I small, peglike, seta II simple and seta III divided, setae I and II close together, gap between setae II and III 5-7 long.

Maxilla. Basal segment of maxillary palp almost $4 \mathrm{x}$ as long as wide with ring organ at the base of apical 1/3, b-seta 3 segmented, middle segment $2 \mathrm{x}$ as long as basal or apical segment.

Mentum and $M$ appendage. Dorsomentum without teeth, a sclerotized complex on each side of base of $M$ appendage and from which labial vesicles on each side ending in 2 overlapping, blunt points; $M$ appendage triangular and snout-like; labial vesicle elongated; pseudoradula relatively narrow band, narrowed towards apex, granulation comprising of 7-8 closely adjacent parallel rows.

Ligula and paraligula. With concave row of 5 teeth, almost $2 \mathrm{x}$ as long as apical width, apical $1 / 3$ brownish black, middle tooth $2 \mathrm{x}$ as long as wide, apex of inner tooth distinctly outcurved. Paraligula bifid about 0.43 length of ligula, outer point $2 \mathrm{x}$ as long as finner point.

Pecten hypopharyngis. With 17-18 teeth more or less equal in length, outermost tooth smaller.

Body. Without fringe of swim-setae. Anal tubules slender, spindle-shaped, about $5 \mathrm{x}$ as long as wide. Posterior parapod bearing a subbasal simple seta. Procercus about $3 \mathrm{x}$ as long as wide with 7 anal and 2 strong supraanal setae. Claws of posterior parapod simple, larger claws with small, fine points on inner margin.

\subsection{Systematics}

In the key of adult tanypod males of Holarctic chironomids (Murray \& Fittkau 1989) Coffmania will key to couplet 21, consisting of the genera Hayesomyia Murray and Fittkau, Telopelopia Roback, Helopelopia Roback and Conchapelopia Fittkau. Similarly in the key of tanypod pupae of Holarctic chironomids (Fittkau \& Murray 1986), Coffmania will key to couplet 28, consisting of the genera Conchapelopia, Meropelopia Roback, Telopelopia and Helopelopia. The new taxon bears diffused characters with the other genera of the Thienemannimyia group and seems to be allied to genus Conchapelopia nepalicola-group (Murray 1976) of the Conchapelopia and Telopelopia Roback because of the presence of scutal tubercle. The median volsella comes nearer to those of Rheopelopia Fittkau and Thienemannimyia Fittkau. The new species Coffmania adiecta proposed under the new genus also possesses elongate, finger-like lateral lobe as noted in some Rheopelopia (maculipennis-group) and Hayesomyia. The setae on the posterior border of tergite IX either form a continuous row as in Thienemannimyia, Rheopelopia, nepalicola-group and Hayesomyia or absent as in Conchapelopia, Helopelopia and Telopelopia. $\mathrm{Ta}_{3}$ of midleg possesses either tarsal brush like that of Conchapelopia, Helopelopia or without tarsal brush as in Thienemannimyia, Telopelopia, Meropelopia and Hayesomyia. Apically bifurcate horn sac of pupa bears some resemblances with that of Conchapelopia pallidula (Meigen 1818). Similarly, LS setae on abdominal segments VII and VIII are like those of Conchapelopia and Hayesomyia. In the same way, apex of anal lobe is moderately to strongly hooked as in Rheopelopia. The larva seems to be a typical Conchapelopia larva in respect to antenna, b-seta of maxillary palp, mandible, ligula and subbasal seta of posterior parapods. Male pupa of Pentaneurini sp.1 described by Roback \& Coffman (1989) from Southern India bears close affinities with the Coffmania animispina proposed in the new genus in median volsella of male hypopygium, thoracic horn, shagreen pattern, anal lobe and G.F. but differs in location of LS setae on segments VII and VIII, ALR. AR and b-seta of larva of Pentaneurini sp. 1 differ with the new genus. It is worthy to mention that the pupa being described here almost conforms with that of Pentaneurini sp. 1 described by Roback \& Coffman (1989) from Southern India. Therefore, in our opinion, the pupa of Pentaneurini sp. 1 should be treated under the new genus Coffmania. 
3.3. Key to the male imagines of the genus Coffmania gen. n. from Darjeeling-Sikkim Himalayas

1. Median volsella with elongate finger-like lateral lobe. Ta3 of mid leg with tarsal brush adiecta sp. $\mathbf{n}$.

- Median volsella without lateral lobe. Tarsal brush on $\mathrm{Ta}_{3}$ of mid leg absent ..... animispina sp. $\mathrm{n}$.

3.4. Key to the pupae of the genus Coffmania gen. $n$. from Darjeeling-Sikkim Himalayas

1. Plastron plate occupying 0.75 length of the thoracic horn. Inner border of anal lobe lacking spinules adiecta sp. $\mathrm{n}$.

- Plastron plate occupying 0.40-0.65 length of the horn. Inner border of anal lobe with 8-11 spinules animispina sp. $\mathrm{n}$.

\subsection{The Thienemannimyia group}

Coffmania adiecta sp. n. (Figs. 1 A-B, 2 A-F)

Type material. Holotype ơ (Type no. B.U.Ent. 230) with pupa [reared], Sikkim, Jorethang, 08-IX-1996, coll. N. Hazra. Paratype 10 with pupa, data as holotype.

- Male imago $(\mathrm{n}=1)$

Total length 3.25 ; wing length 1.74 ; total length / wing length 1.87; wing length / profemur length 1.74.

Head. Eye with 139 long dorsomedial extension. AR 1.32; length of flagellomeres (I-XIV) : 41, 22, 35, $35,35,35,35,35,35,35,35,35,455,92$. Temporal setae 14 (4 IV, 7 OV, 3 Po). Clypeus with 29 setae. Length of palpomeres : $55,78,165,195,225$. CA 0.57 ; CP 0.75 .

Thorax. Acrostichals 33 biserial between the vittae and 15 between scutal tubercle and prescutellar field; dorsocentrals 30 , prealars 18 , supraalar 1 ; scutellum with 16 large and 17 small setae.

Wing (Fig. 1A). VR 0.87; CR 0.93; costal extension 48; squama with 22 setae.

Leg. Spur of fore tibia 37 long bearing 7 lateral teeth, spurs of mid tibia 46 and 48 long bearing 7 and 8 lateral teeth, spurs of hind tibia 41 and 66 long bearing 6 lateral teeth each. $\mathrm{Ta}_{3}$ of mid leg with tarsal brush.

Lengths and proportions of leg segments:

\begin{tabular}{|c|c|c|c|c|c|c|c|c|c|c|c|}
\hline & $\mathbf{F e}$ & $\mathrm{Ti}$ & $\mathrm{ta}_{1}$ & $\mathrm{ta}_{2}$ & $\operatorname{ta}_{3}$ & $\mathrm{ta}_{4}$ & $\mathbf{t a}_{5}$ & LR & BV & SV & BR \\
\hline $\mathrm{p}_{1}:$ & 810 & 960 & 840 & 450 & 315 & 225 & 120 & 0.87 & 2.35 & 2.68 & 4.33 \\
\hline $\mathrm{p}_{2}:$ & 885 & 970 & 570 & 277 & 195 & 150 & 90 & 0.58 & 3.40 & 4.26 & 4.61 \\
\hline $\mathrm{p}_{3}:$ & 780 & 1065 & 840 & 450 & 330 & 225 & 120 & 0.78 & 2.38 & 2.73 & 5.71 \\
\hline
\end{tabular}

Abdomen. Tergite IX without transverse row of setae.

Hypopygium (Fig. 1B).Gonocoxite 148 long, $1.5 \mathrm{x}$ as long as broad; median volsella (Fig. $1 \mathrm{~B}_{1}$ ) broad, setose, swollen apically with elongate finger-like lateral lobe; gonostylus slender, curved 140 long with 11 long megaseta; phallapodeme 107 long, sternapodeme 92 long; HR 1.05; HV 2.32.

- Female : unknown.

- Pupa (n=1)

Total length of exuviae 4.07. Pale brown in colour.

Cephalothorax. Thoracic horn (Fig. 2A) 322 long, Thr 1.65, plastron plate occupying 0.75 horn length; thoracic comb as in the Fig. $2 \mathrm{~A}_{1}$.

Abdomen. Scar on tergite I (Fig. 2B) 157 long, occupying 0.80 length of the segment I. Segments I-VIII with mostly simple (Fig. $2 \mathrm{C}_{1}$ ) and posteromedially simple, bifid and multibranched spinules (Fig. $2 \mathrm{C}_{2}$ ). Arrangement of setae on segment IV as in the Fig. 2D. Segment VII (Fig. 2E) with 202 long 4 LS setae placed $0.57,0.67,0.76$ and 0.84 from base; segment VIII (Fig. 2F) with 480 long 5 LS setae placed $0.49,0.58,0.76$, 0.88 and 0.92 from base. Anal lobe (Fig. 2F) 322 long, 333 wide without inner spinules and with several outer spinules plus 2 anal macrosetae placed 0.41 and 0.55 from base; G/F 0.70 in male; ALR 1.94.

- Larva : unknown.

\section{Remarks}

Owing to presence of a lateral lobe on the median volsella of the male hypopygium, the species has been named as Coffmania adiecta. The diagnosis characters of the species are :

Male imago. i) Median volsella broad, setose swollen epically with elongate finger-like lateral lobe, ii) AR 1.32, iii) squamal setae 22, iv) HR 1.05 and v) $\mathrm{Ta}_{3}$ of mid leg with tarsal brush.

Pupa. i) Plastron plate occupying 0.75 length of the horn, ii) Thr 1.65 , iii) $\mathrm{LS}_{1}$ seta on segment VII at 0.57 segment length, iv) apex of anal lobe moderately hooked, v) ALR 1.94 and vi) G/F 0.70.

Coffmania animispina sp. n. (Figs. 3 A-E, 4, 5 A-F, $6 \mathrm{~A}-\mathrm{G})$

Type material. Holotype ơ with pupa [reared] (Type no. B.U. Ent. 231), Sikkim, Tadong, 08-IV-1996, coll. N. Hazra. Paratypes $30^{\circ} 0^{\prime \prime}$ and 3 oq with larvae and pupae [reared], data same as above; $1 \sigma^{\prime \prime}$ and $1 \%$ with pupae [reared], Sikkim, Jorethang, 27-V-1996, coll. N. Hazra; $1 \%$ with larva and pupa [reared], West Bengal, Mirik, 03-IX-1996, coll. N. Hazra. 

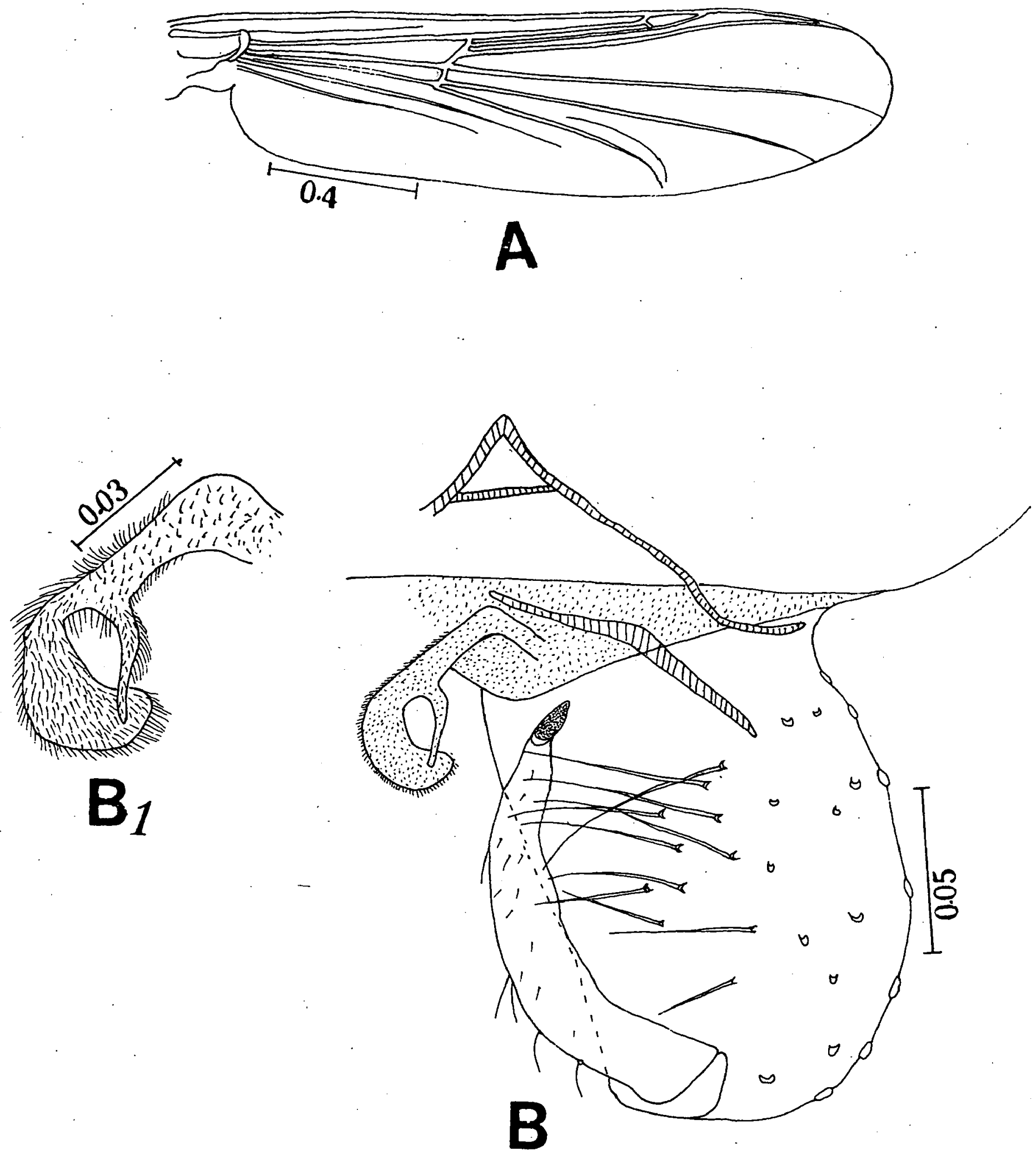

Fig. 1. Male imago of Coffmania adiecta n. sp. : A. wing; B. hypopygium ; B $_{1}$. enlarged median volsella. Fig. 1. Imago mâle de Coffmania adiecta $n$. sp. : A. aile; B. hypopyge $; B_{1}$. volsella médiane agrandie. 

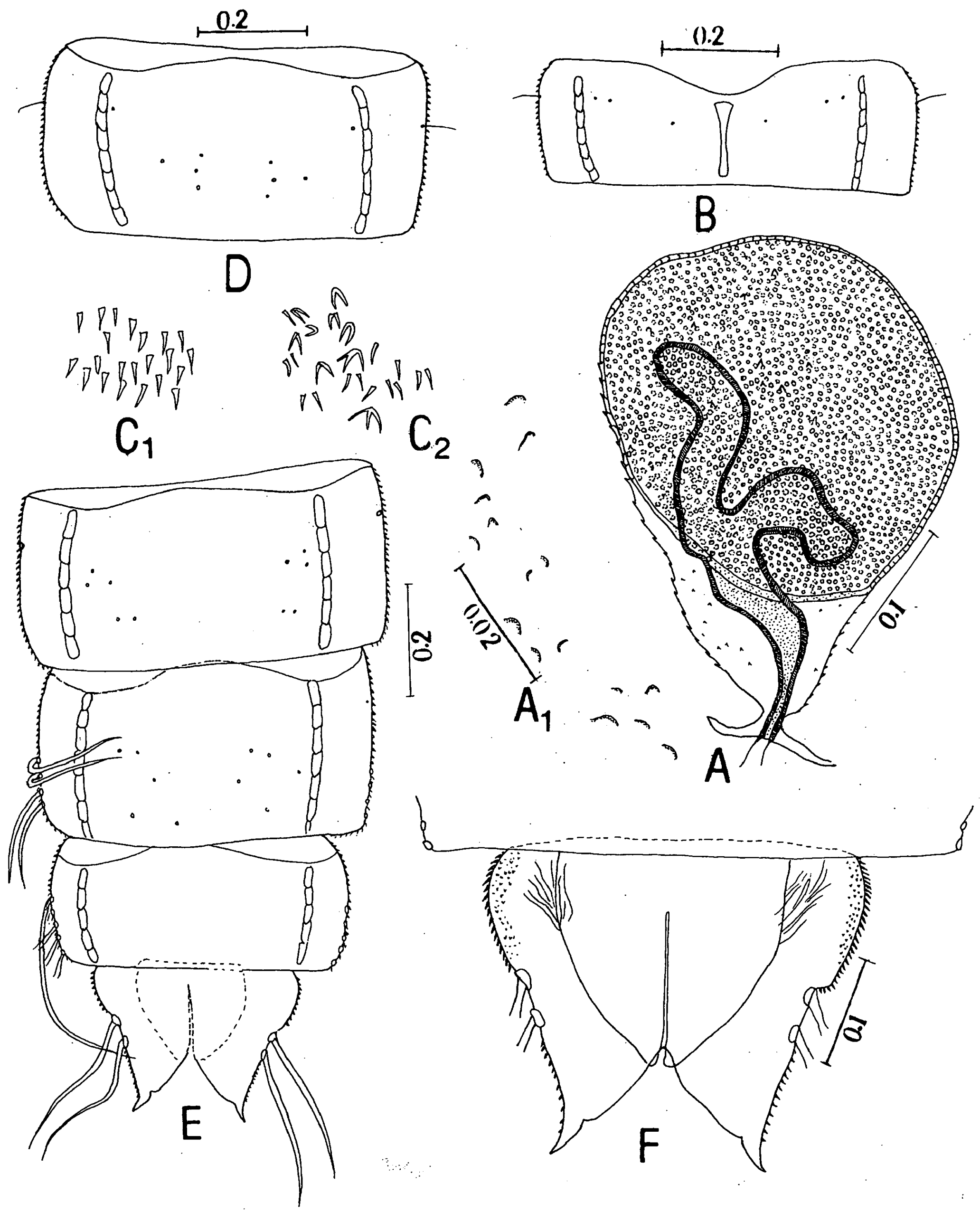

Fig. 2. Pupa of Coffmania adiecta $n$. sp. : A. thoracic horn; $A_{1}$. thoracic comb ; B. tergite $I ; C_{1}$. shagreen on anterior part of tergite IV; $C_{2}$. shagreen on posteromedial part of tergite IV; D. tergite IV; E. segments VI-VIII and anal lobe; F. anal lobe and male genital sac.

Fig. 2. Nymphe de Coffmania adiecta n. sp.: A. corne thoracique; $A_{1}$ peigne thoracique $; B$. tergite $I ; C_{1}$. chagrin sur la partie antérieure du tergite IV; $\mathrm{C}_{2}$. chagrin sur la partie postéro-médiane du tergite IV; D. tergite IV; E. segments VI-VIII et lobe anal; F. lobe anal et sac génital mâle. 

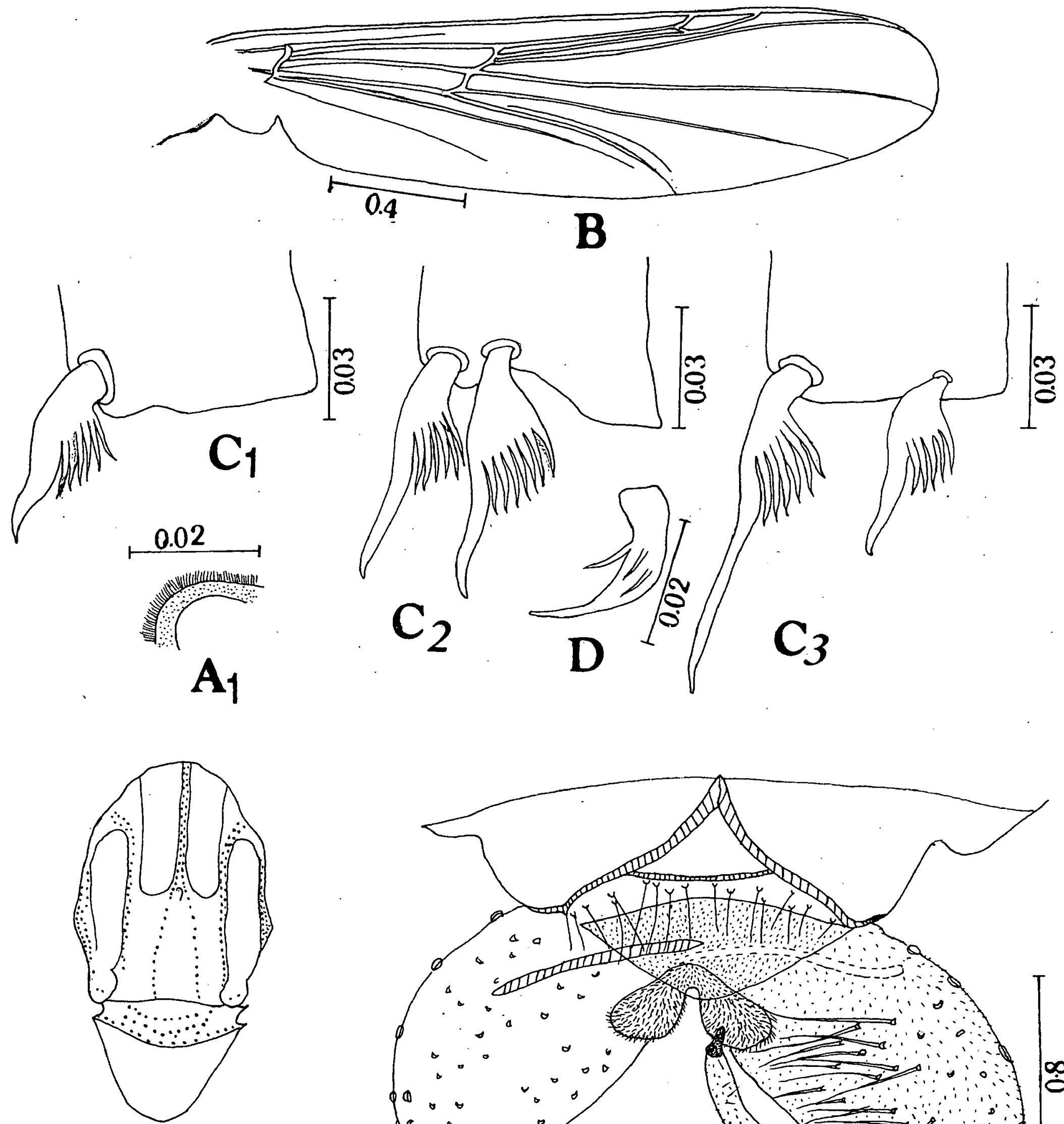

A

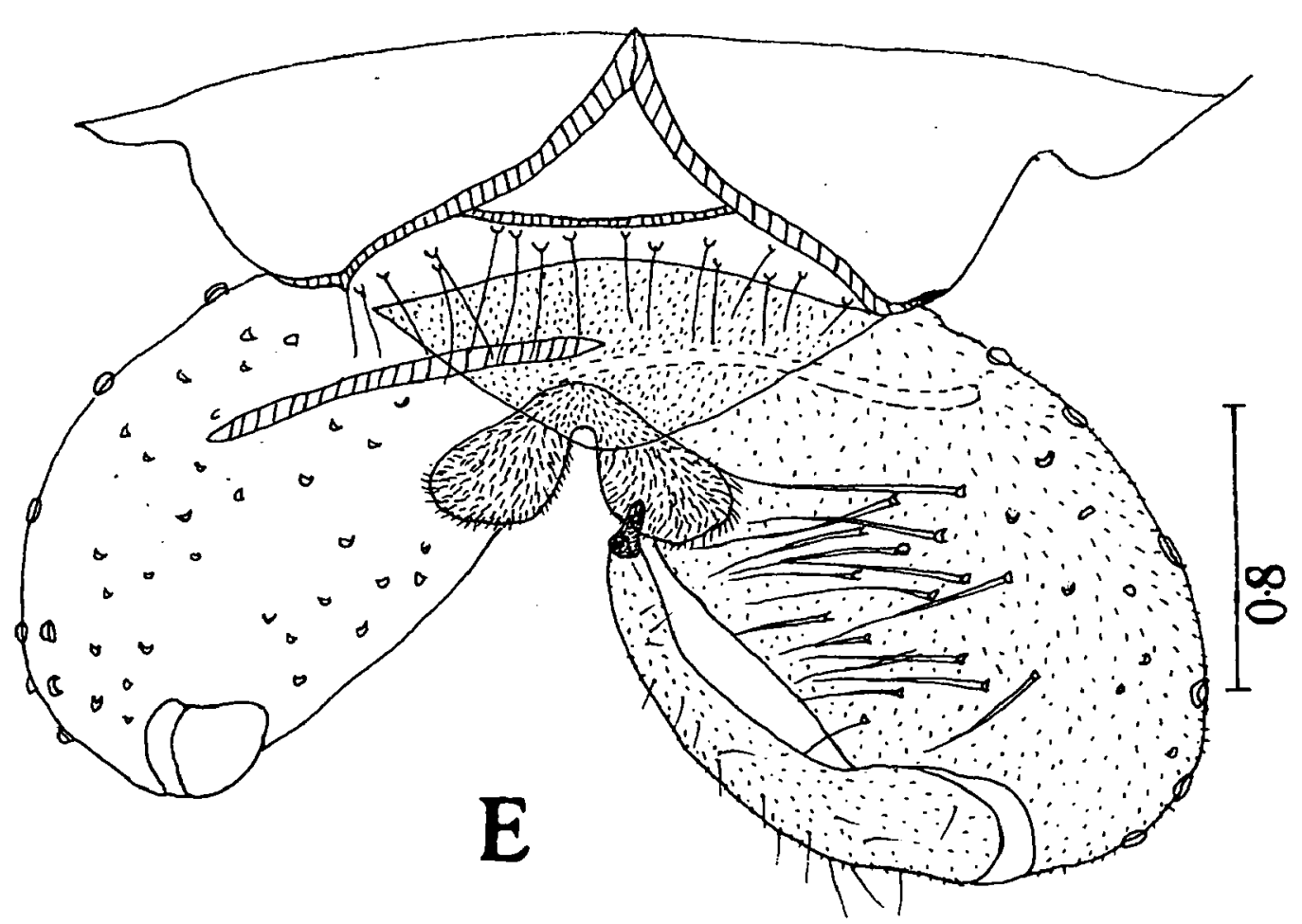

Fig. 3. Male imago of Coffmania animispina $\mathrm{n}$. sp. : A. thorax ; $\mathrm{A}_{1}$. scutal tubercle; $\mathrm{B}$. wing; $\mathrm{C}_{1}-\mathrm{C}_{3}$. tibial spurs on fore leg, mid leg and hind leg ; D. claw; E. hypopygium.

Fig. 3.Imago mâle de Coffmania animispina n. sp. : A. thorax; $A_{1}$. tubercule scutal ; B. aile; $C_{1}-C_{3}$. éperons des tibias des pattes antérieures, moyennes et postérieures; D. griffe; E. hypopyge. 


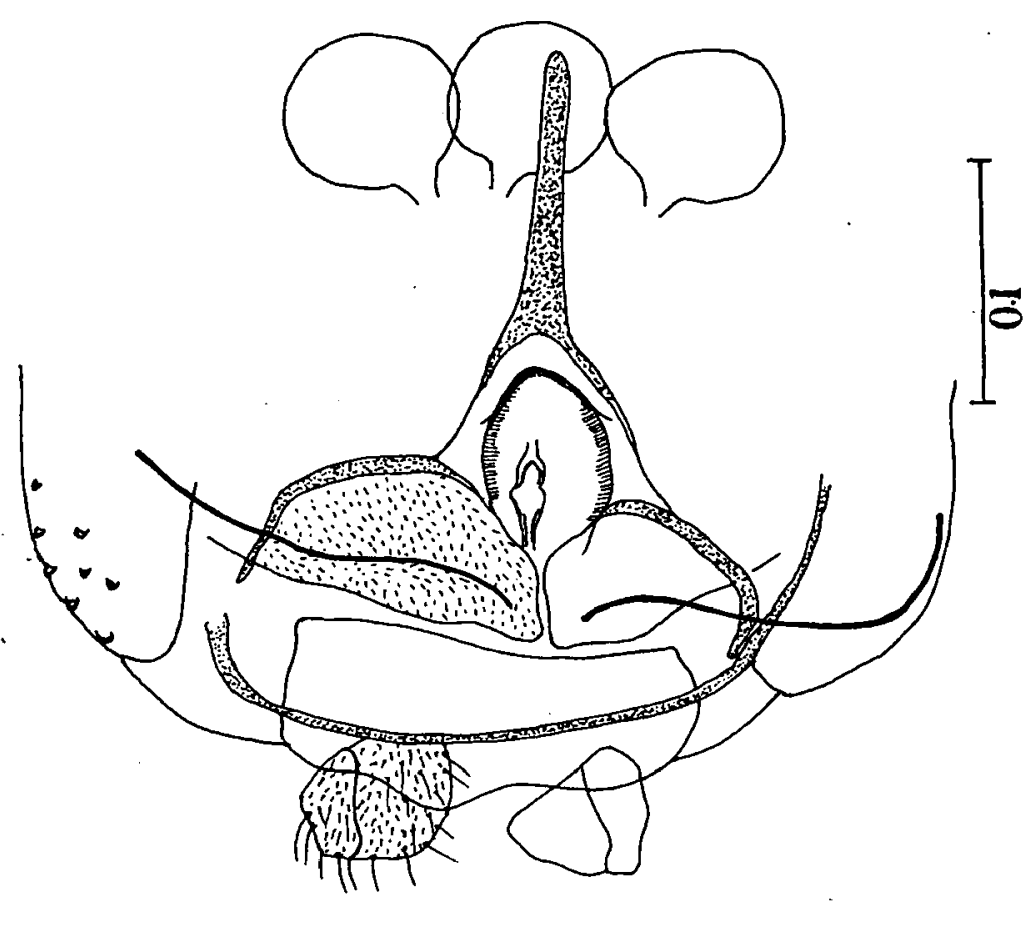

Fig. 4. Female genitalia of Coffmania animispina $\mathrm{n}$. sp. Fig. 4. Genitalia femelle de Coffmania animispina n. $\mathrm{sp}$

- Male imago ( $n=4$, except when otherwise stated)

Total length 3.14-3.77; wing length 1.52-1.85; total length / wing length 1.91-2.03; wing length / length of profemur 1.78-2.15.

Head. Eyes with 158-180 long dorsomedial extension. AR 1.14-1.36; length of flagellomeres (I-XIV) : 29-33, 18-26, 30-33, 33-37, 33-37, 33-37, 33-37, 33$37,33-37,33-37,33-37,33-37,359-433,78-81$. Temporal setae 15-18 (4-5 IV, 8-9 OV, 3-4 Po). Clypeus with 16-24 setae. Length of palpomeres : $37-48$, 74-82, $120-150,165-187,225-285$. CA 0.51-0.57; CP 0.720.78 .

Thorax (Fig. 3A). Acrostichals 17-36 biserial between the vittae, 10-26 diverging in front of the scutal tubercle (Fig. 3A1) and extending to the prescutellar field; dorsocentrals 23-32, prealars 12-20, supraalars 2; scutellum with 10-21 large and 13-18 small setae.

Wing (Fig. 3B). VR 0.82-0.88; CR 0.91-0.93; sensilla camponiformia 24-26; costal extension 55-59 long; squama with 20-23 setae.

Leg. Spur of fore tibia (Fig. 3C $\mathrm{C}_{1}$ ) 33-41 long bearing 6-8 lateral teeth, spurs of mid tibia (Fig. $3 \mathrm{C}_{2}$ ) unequal 39-42 and 44-50 long bearing 7 and 8 lateral teeth, spurs of hind tibia (Fig. $3 \mathrm{C}_{3}$ ) 33-40 and 59-70 long bearing 5 and 6 lateral teeth; width at the apex of fore tibia 39-45, mid tibia 41-52 and hind tibia 41-48; claws as in the Fig. 3D.

Lengths and proportions of leg segments:

\begin{tabular}{|c|c|c|c|c|c|}
\hline $\mathrm{Fe}$ & $\mathbf{T i}$ & $\mathrm{ta}_{1}$ & $\mathrm{ta}_{2}$ & $t_{3}$ & $\mathbf{t a}_{4} \cdot \operatorname{ta}_{5}$ \\
\hline $\mathrm{p}_{1}: \quad 690-870$ & $0 \quad 810-1005$ & $705-915$ & $330-450$ & $240-315$ & $165-225 \quad 105-120$ \\
\hline $\mathrm{p}_{2}: 765-945$ & $5750-930$ & $465-585$ & $210-270$ & $165-210$ & $127-165 \quad 82-105$ \\
\hline \multirow[t]{2}{*}{$\mathrm{p}_{3}:$} & $0930-1162$ & $750-930$ & $375-510$ & $285-375$ & $165-240 \quad 105-120$ \\
\hline & LR & BV & & SV & BR \\
\hline $\mathrm{p}_{1}$ : & $0.87-0.91$ & $2.22-2$. & & $2.90-2.94$ & $4.00-4.66$ \\
\hline $\mathrm{P}_{2}$ : & $0.62-0.63$ & $3.28-3$. & & $3.90-4.04$ & $4.97-5.16$ \\
\hline$P_{3}$ : & 0.80 & $2.15-2$. & & $2.76-2.83$ & $5.83-6.00$ \\
\hline
\end{tabular}

Abdomen. 16-18 setae on posterior border of tergite IX forming a single row or setae absent.

Hypopygium (Fig. 3E). Gonocoxite 129-155 long, $1.4 \mathrm{x}$ as long as broad; median volsella setose, ovoid or triangular in shape; gonostylus 129-144 long, slender, uniformly tapered with 13-16 long megaseta; sternapodeme 75-96 long, phallapodeme 70-92 long; HR 1.00-1.07; HV 2.43-2.74.

- Female imago ( $n=4$, except when otherwise stated)

Similar to male with usual sex differences :

Genitalia (Fig. 4). Gonapophysis VIII with inner margin of ventrolateral lobe strongly projecting towards inner margin of opposite lobe; vaginal opening oval, hinge weakly sclerotized with apex directed distolaterally; gonocoxite VIII with 6-8 setae; cercus 4048 long; seminal capsule 51-62 in diameter; notum 92111 long.

- Pupa ( $\mathrm{n}=5$, except when otherwise stated)

Length of exuviae 4.25-4.66 long, pale brown in colour.

Cephalothorax. Thoracic horn (Fig. 5A) 277-345 long, Thr 1.72-2.1, plastron plate occupying 0.40-0.65 horn length; thoracic comb small, as in the Figs. $5 \mathrm{~A}_{1}$. $\mathrm{Dc}_{1}, \mathrm{Dc}_{2}$ and Sa 33-48 long.

Abdomen. Scar on tergite I (Fig. 5B) 150-195 long, cylindrical, occupying 0.83-0.92 length of the segment. Segment I with simple as well as bifid spinules, segments II-VIII with mostly simple spinules (Fig. $5 \mathrm{C}_{1}$ ) and posteromedially simple, bifid and multibranched spinules (Fig. $5 \mathrm{C}_{2}$ ). Setal pattern on tergite IV as in the Fig. 5D; 210-300 long 4 LS setae (Fig. 5E) placed on segment VII at 0.54-0.68, 0.65-0.76, 0.77-0.84, and 0.86-0.92 of segment length; $450-525$ long 5 LS setae on segment VIII at $0.50-0.58,0.62-0.69,0.71-$ 


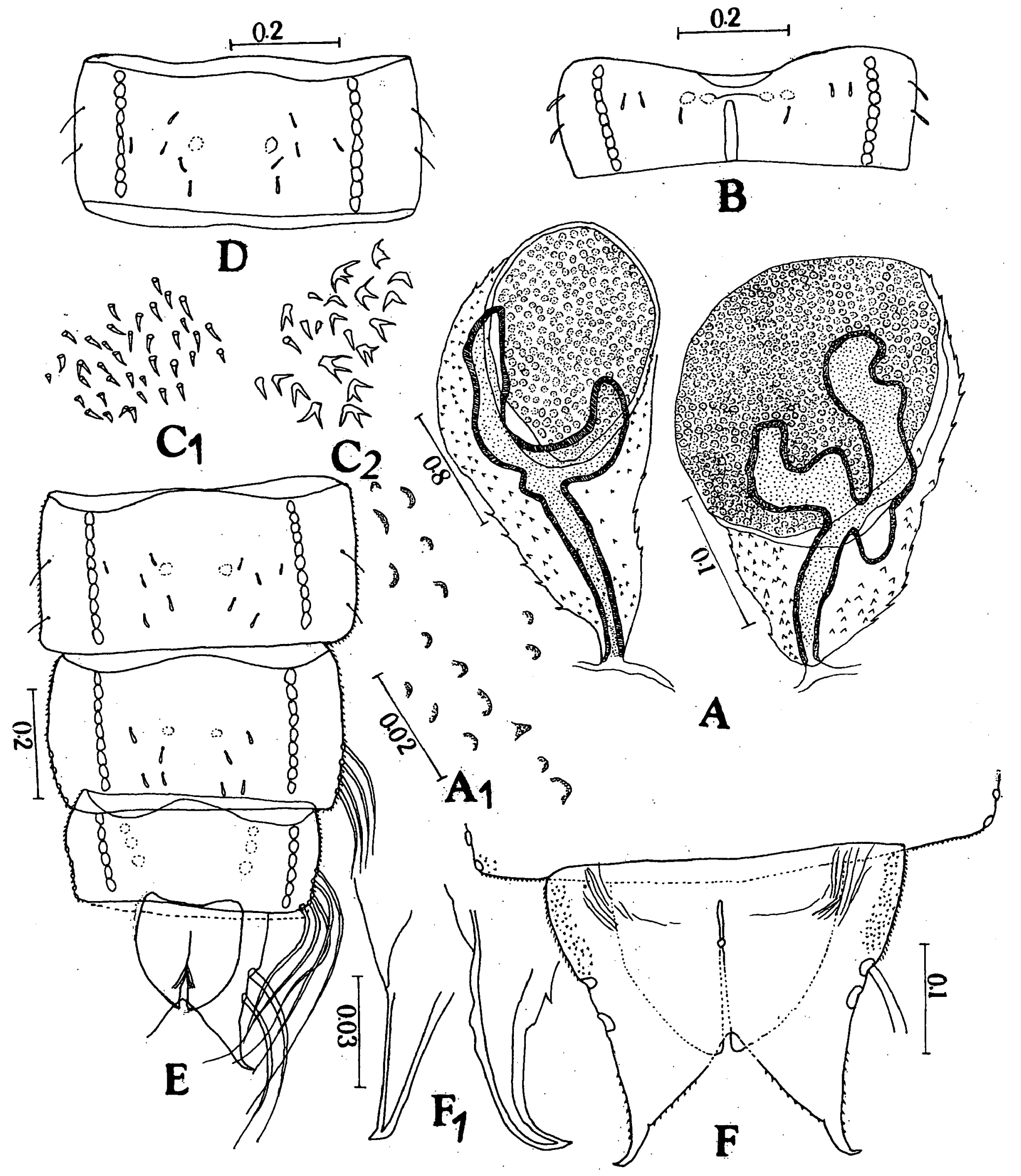

Fig. 5. Pupa of Coffmania animispina $n$. sp. : A. thoracic horn ; $A_{1}$. thoracic comb ; B. tergite $I ; C_{1}$. shagreen on anterior part of tergite IV; $C_{2}$. shagreen on posteromedial part of tergite IV; D. tergite IV; E. segments VI-VIII and anal lobe ; F. anaI lobe and male genital sac ; F1. enlarged apex of anal lobe.

Fig. 5. Nymphe de Coffmania animispina n. sp. : A. corne thoracique; $\mathrm{A}_{1}$. peigne thoracique $; \mathrm{B}$. tergite $\mathrm{I} ; \mathrm{C}_{1}$. chagrin sur la partie antérieure du tergite IV ; $\mathrm{C}_{2}$. chagrin sur la partie postéro-médiane du tergite IV; D. tergite IV; E. segments VI-VIII et lobe anal; F. lobe anal et sac génital mâle; F1.apex agrandi du lobe anal. 

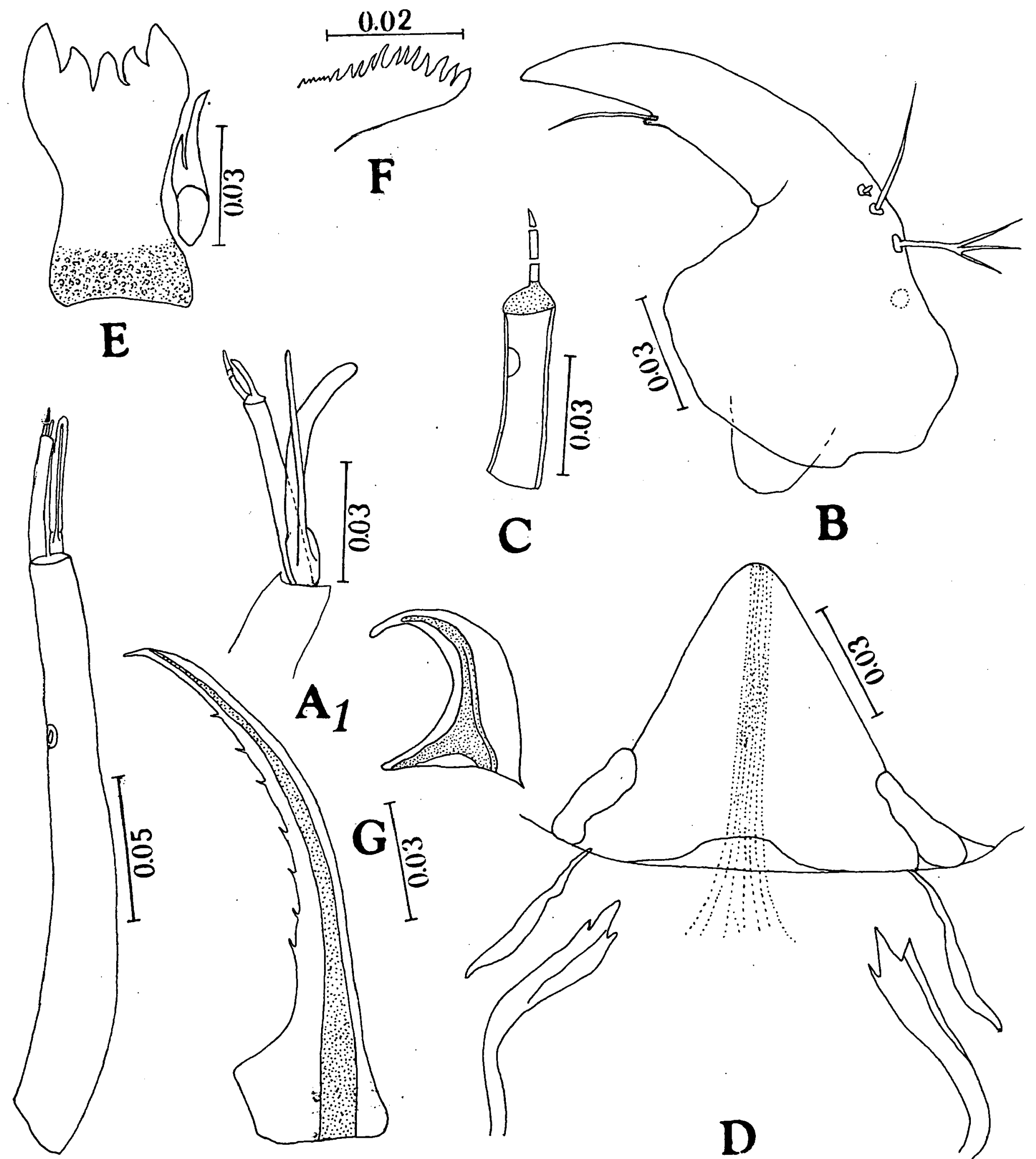

A

Fig. 6. Larva of Coffmania animispina $\mathrm{n} . \mathrm{sp}$. : A. antenna ; $\mathrm{A}_{1}$. apex of antenna ; B. mandible; C. maxillary palp ; D. mentum and m appendage; E. ligula and paraligula; F. pecten hypopharyngis; G. claws of posterior parapod.

Fig. 6. Larve de Coffmania animispina n. sp. : A. antenne ; $\mathrm{A}_{1}$. apex de l'antenne ; B. mandibule; C. palpe maxillaire; D. mentum; E. ligula et paraligula; F. peigne de l'hypopharynx; G. crochets des parapodes postérieurs. 
$0.80,0.83-0.90$ and $0.94-0.97$ of segment length. Anal lobe (Fig. 5F) 330-390 long, 300-338 wide with 8-11 inner spinules, several outer spinules and anal macrosetae placed at $0.39-0.43$ and $0.52-0.56$ lobe length; G/F 0.65-0.71 in male; ALR 2.18-2.31.

- Larva ( $n=3$, except when otherwise stated)

Total length 5.40-6.00. Head capsule brown in colour, cephalic index 0.64-0.70.

Antenna (Figs. 6A-A $)$ ). AR 3.45-3.87; length of antennal segments (I-IV) : 211-222, 44-50, 6-7, 5-5.5; style 7-10 long; blade 53-56 long, accessory blade 49-53 long.

Mandible (Fig. 6B). 111-122 long; apical tooth 26-30 long; seta subdentalis 19-22 long.

Maxilla (Fig. 6C). Basal segment of palp 40-44 long; length of segments of b-seta 3, 6 and 3 .

Mentum and $M$ appendages (Fig. 6D). Labial vesicle 18-22 long; pseudoradula 77-85 long, basal width 11-15.

Ligula (Fig. 6E). 77-86 long, middle tooth 9-11 long and inner tooth 11-14 long.

Paraligula (Fig. 6E). 35-37 long; inner point 7-9 long and outer point 15-18 long.

Pecten hypopharyngis (Fig. 6F). 17-18 teeth.

Body. Anal tubule 111-140 long, 22-29 wide; subbasal seta 170-185 long; procercus 88-93 long, 28-32 wide with 375-450 long anal setae; supraanal seta 345-375 long; claws of posterior parapods as in the Fig. 6G.

\section{Remarks}

In view of the presence of spines in the inner border of the anal lobe of pupa, the species has been named as Coffmania animispina. The diagnosis characters of the species are :

Male imago. i) Median volsella setose, ovoid or triangular in shape, ii) tergite IX with $16-18$ setae in transverse row or without setae, iii) squamal setae 20-22, iv) AR 1.14-1.36 and v) HR 1.00-1.07.

Pupa. i) Plastron plate occupying 0.40-0.65 length of the horn, ii) Thr 1.72-2.10, iii) $\mathrm{LS}_{1}$ seta on segment VII at 0.54-0.68 segment length, iv) apex of anal lobe moderately or strongly hooked, $v$ ) inner border of anal lobe with 8-11 spinules, vi) ALR 2.18-2.31 and vii) $\mathrm{G} / \mathrm{F}$ 0.65-0.71 in male.

Larva. i) Cephalic index 0.64, ii) AR 3.4-3.9, iii) blade shorter than flagellum, iv) basal tooth very short, v) length of segments of b-seta 3,6 and 3, vi) ligula bearing concave row of teeth, vii) paraligula 0.43 length of ligula, viii) pseudoradula consisting of 7-8 parallel rows and ix) 2 strong supraanal setae.

\section{Ecology}

Immatures are rheobiontic and embenthic living in cool, small sized, shallow springs. They prefer algal mats of more or less hygropetric biotopes with slow to moderate flow. The tanypod larvae remain usually in close association with orthoclad larvae of genus Paracricotopus Thienemann and Harnisch which are considered as their predominant food in addition to algae, detritus and other chironomid larvae.

\section{Acknowledgements}

Thanks are due to the Department of Science \& Technology, Govt. of India, New Delhi for providing fund for the project and to the Head of the Department of Zoology, University of Burdwan and Postgraduate Department of Zoology, Darjeeling Govt. College for laboratory facilities. We express our indebtness to Dr. Xinhua Wang, Department of Biology, Nankai University for kindly reading the manuscript and for making valuable comments.

\section{References}

Das Gupta S.K. \& Wirth W.W. 1968. - Revision of Oriental species of Stilobezzia Kieffer (Diptera : Ceratopogonidae). Bull. U.S. Nat. Mus., 283 : 1-264.

Fittkau E.J. \& Murray D.A. 1986. - The pupae of Tanypodinae (Diptera : Chironomidae) of the Holarctic region - Keys and diagnoses. In Wiederholm, T. (ed.) Chironomidae of the Holarctic region, Keys and diagnoses, Part 2 - Pupae. Ent. Scand,. Suppl. $28: 31-113$.

Meigen J.W. 1818. - Systematische Beschreibung der bekannten europäischen zweiflugeligen Insekten. Erster Teil Aachen.

Murray D.A. 1976. - Four new species of Conchapelopia Fittkau from Nepal with a discussion of the phylogeny of the nepalicolagroup (Diptera : Chironomidae). Ent. Scand., Suppl. 7 : 293-301.

Murray D.A. \& Fittkau E.J. 1989. - The adult males of Tanypodinae (Diptera : Chironomidae) of the Holarctic region - Keys and diagnoses. In Wiederholm, T. (ed.) Chironomidae of the Holarctic region, Keys and diagnoses, Part 3 - Adult males. Ent. Scand., Suppl. $34: 37-123$.

Roback S.S. \& Coffman W.P. 1989. - Tanypodinae pupae from Southern India (Diptera : Chironomidae). Proc. Acad. Nat. Sc. Philad., $141: 85-113$.

Sæther O.A. 1974. - Morphology and terminology of female genitalia in Chironomidae (Diptera). Ent. Tidskr., Suppl. 95 : 216-224.

Sæther O.A. 1977. - Female genitalia in Chironomidae and other Nematocera : morphology, phylogenies, keys. Bull. Fish. Res. Bd. Can., 197 : 1-209.

Sæther O.A. 1980. - Glossary of Chironomid morphology terminology (Diptera : Chironomidae). Ent. Scand., Suppl. 14: 1-51. 